\title{
Ley de Migración mexicana: Algunas de sus inconstitucionalidades
}

\author{
KARLOS A. CASTILLA JUÁREZ*
}

ReSUMEN: La Ley de Migración mexicana cumple en el año 2014 tres años de vigencia. Su contenido, que introduce importantes avances que buscan la garantía y protección de los derechos humanos de las personas migrantes, hasta hoy no ha mostrado toda su eficacia en la realidad. Además, dicha ley no ha sido todavía analizada a profundidad por las autoridades jurisdiccionales mexicanas para determinar la compatibilidad de sus normas con el bloque constitucional de derechos humanos (Constitución-tratados) establecido en el artículo $1^{\circ}$. constitucional. Ante eso, en este documento se estudian algunas de las posibles inconstitucionalidades que contiene la Ley de Migración, buscando que puedan ser debatidas y, con ello, sean expulsadas del sistema jurídico mexicano con el fin de hacer posible la creación de una política migratoria que de manera más efectiva respete los derechos humanos reconocidos en la Constitución y en los tratados a toda persona en México.

PALABRAS ClaVE: Ley de Migración, Constitución, tratados, derechos humanos, inconstitucionalidad.

\footnotetext{
* Miembro del Grupo de Investigación Interdisciplinario en Inmigración de la Universitat Pompeu Fabra (GriIIm-Upf). Becario del Consejo Nacional de Ciencia y Tecnología (Conacyt), México.
} 
ABSTRACT: Mexico's Migration Law had been in effect for three years by 2014. It enacted significant advances that sought to guarantee and protect migrants' human rights, which have yet to be reflected in reality. Furthermore, this Law has not yet been comprehensively analyzed by Mexican judicial authorities to determine the compatibility of its norms with the constitutional package of human rights protections (Constitution-Treaties) established in the $1^{\text {st }}$ article of the Constitution. With this in mind, this article examines some of the potential unconstitutionalities contained within the Migration Law, seeks to explore whether they can be debated, and from this, determine whether they may be excised from Mexico's legal system with the aim of making possible the creation of a migratory policy that more effectively respects the human rights recognized in the Constitution and in the treatment of all people in Mexico.

KEYWORDs: Migration Law, constitution, treaties, human rights, unconstitutionality. 


\section{INTRODUCCIÓN}

E

126 de mayo de 2013 se cumplieron tres años de vigencia de la Ley de Migración (LM) mexicana, ${ }^{1}$ aunque por las características de algunas de sus disposiciones entró en vigor con la implementación de su reglamento, aprobado con un retraso de más de 10 meses, el 28 de septiembre de 2012. ${ }^{2}$ Con poca responsabilidad y compromiso de diversas autoridades mexicanas, se puso en marcha lo que desde la normatividad pretende ser una política migratoria del Estado mexicano acorde con las necesidades de la migración humana del siglo xxi.

En sus tres primeros años, la Lm ha sido reformada en dos ocasiones en junio de 2013 para mejorar la protección de niños, niñas y adolescentes migrantes (artículo 112 de la LM), y para precisar algunos aspectos del Servicio Profesional de Carrera que creó dicha ley (fracción xxvir del artículo 3 y artículo 25 de la LM); pero al menos hasta junio de 2014 no existen registros jurisprudenciales que den muestra del análisis de la constitucionalidad de sus disposiciones por los jueces federales, ${ }^{3}$ quienes tienen competencia para revisarlo, salvo el análisis que hizo en agosto de 2012 la Suprema Corte de Justicia de la Nación en una serie de casos vinculados con la aplicación del artículo décimo transitorio de la ley $y^{4}$ relacionado con la aplicación del artículo 159 de la misma y el artículo 138 de la Ley

${ }^{1}$ En este documento se analiza el texto vigente al 30 de junio de 2014.

${ }^{2}$ El Reglamento debió ser expedido dentro del término de 180 días contados a partir de la entrada en vigor de la ley, esto es, antes del 25 de noviembre de 2011, de conformidad con el artículo tercero transitorio de la referida Ley de Migración (LM).

${ }^{3}$ Por jueces federales entiendo jueces de distrito, magistrados de circuito (Tribunales Unitarios y Colegiados de Circuito) y ministros (Suprema Corte de Justicia de la Nación).

4 Véanse, entre otros, amparos en revisión 8/2012, 15/2012, 30/2012, 56/2012, 96/2012, 194/2012, 218/2012, 283/2012, 342/2012, 358/2012, 392/2012, 401/2012, de los que derivaron, las tesis jurisprudenciales: 1a./J. 117/2012 (10a.), de rubro: «Migración. El artículo décimo transitorio de la ley relativa, no constituye una ley privativa de las prohibidas por el artículo 13 de la Constitución Política de los Estados Unidos Mexicanos»; 1a./J. 118/2012 (10a.) de rubro: «Migración. El artículo décimo transitorio de la ley relativa, no viola el principio de exacta aplicación de la ley en materia penal previsto en el artículo 14, párrafo tercero, de la Constitución Política de los Estados Unidos Mexicanos»; entre otras más. 
General de Población (LGP) ${ }^{5}$ que quedaba sin vigencia (procedimientos penales por delitos en materia migratoria).

La falta de análisis sobre la constitucionalidad de las normas que integran la Lm se debe, por una parte, a que la Comisión Nacional de los Derechos Humanos (CNDH), durante los treinta días naturales siguientes a la fecha de publicación de la ley, consideró que ésta no vulneraba los derechos humanos consagrados en la Constitución y en los tratados internacionales signados por México y, en consecuencia, no promovió acción de inconstitucionalidad; 6 $y$, por otra parte, porque en los casos en que se han planteado inconformidades por el contenido de la LM, incluso por medio del juicio de amparo, no se han hecho valer de manera adecuada argumentos relativos a la inconstitucionalidad de las normas que causan afectación, por lo que no se ha logrado un análisis detallado de ésta, pese a algunos precedentes vinculados con la antigua LGP ${ }^{7}$ que podrían servir para demostrar la continuidad de la vigencia de normas contrarias a derechos humanos (inconstitucionales), pese al cambio legal que se dio. No podemos perder de vista que muchos de los problemas, inconsistencias e incongruencias que hoy encontramos en la LM no surgieron con ésta, sino que están presentes en su mayoría desde la LGP, por lo que la violación de los derechos de las personas migrantes y, con ello, la

${ }^{5}$ La Ley General de Población (LGP) era la norma jurídica que regulaba la migración desde 1974 y hasta antes de la entrada en vigor de la LM.

${ }^{6}$ De conformidad con el artículo 105 de la Constitución y su ley reglamentaria, también podía haber sido promovida la acción de inconstitucionalidad por la Procuraduría General de la República o 33 por ciento de la Cámara de Diputados o de Senadores, pero por especialidad y tener incluso una área encargada del tema (Quinta Visitaduría General). Me parece que la CNDH es quien tenía la mayor responsabilidad en ello.

7 Véanse, por ejemplo, entre otras: Suprema Corte de Justicia de la Nación, tesis jurisprudencial P./J. 80/2007 (9a.) cuyo rubro es: "Suspensión de oficio. Procede decretarla de plano contra la expulsión de extranjeros ordenada por una autoridad administrativa con fundamento en la Ley General de Población»; Tribunales Colegiados de Circuito, tesis aislada I.30.C.681 C (9a.) cuyo rubro es: «Extranjeros, la condición o calidad migratoria que tienen en territorio mexicano no puede restringir su garantía de acceso a la administración de justicia (interpretación del artículo 67 de la Ley General de Población)»; Tribunales Colegiados de Circuito, tesis aislada VI.10.P.37 K (9a.) cuyo rubro es: "Extranjeros. para la procedencia de su demanda de garantías no se requiere que comprueben su legal estancia en el país en términos de lo dispuesto por el artículo 67 de la Ley General de Población».

$152 \frac{\text { SEGUNDO SEMESTRE } 2014}{\text { MIGRACIÓN Y DESARROLLO NÚM. } 23}$ 
inconstitucionalidad de varias disposiciones no fue superada con la nueva ley, sino que más bien fueron replicadas de su antecedente legal.

Ante este panorama, en el presente documento intentaré desarrollar un análisis exhaustivo, pero no taxativo, de las normas o porciones normativas que desde mi punto de vista vulneran los derechos humanos reconocidos en la Constitución y en los tratados internacionales, esto es, que son contrarias al bloque constitucional de derechos humanos.

Con ese fin, en primer lugar, estableceré una descripción general del contenido de la LM para mostrar un panorama de ésta a quienes no tengan familiaridad con su contenido, así como para destacar aquellos aspectos que si logran trascender del papel de la ley a la práctica podrían ser muy efectivos para la protección de los derechos humanos de las personas migrantes. En segundo lugar, explicaré las razones por las cuales sólo hablaré de inconstitucionalidades de la LM, aunque advierto desde ahora que dicho término incluye un análisis no sólo desde las normas de la Constitución, sino también desde los tratados internacionales, pero que, por rigor académico no puedo hablar de inconvencionalidades al no ser ello una labor propia de los jueces nacionales. En tercer lugar, desarrollaré el análisis respecto a por qué muchas normas que integran la LM generan dudas respecto a su constitucionalidad, estableciendo algunos ejemplos concretos de ello, no sólo a partir de afirmaciones generales, como suele hacerse en algunos estudios, sino dando las razones precisas e indicando las normas del bloque constitucional de derechos humanos que de manera particular transgreden. Vale la pena destacar en este punto que, en esta ocasión, no haré el análisis del Reglamento de la LM por no ser el objetivo de este documento, por lo que el análisis estará centrado solamente en la LM. Ya habrá oportunidad de analizar el Reglamento. Finalmente, con todo lo antes analizado, expresaré algunas ideas a manera de conclusión.

\section{La Ley de Migración}

La Ley de Migración fue publicada el 25 de mayo de 2011 en el Diario Oficial de la Federación. Está dirigida a regular el ingreso y salida de personas extranjeras 
y mexicanas, así como el tránsito y estancia de personas extranjeras en el territorio de los Estados Unidos Mexicanos. Su antecedente normativo más cercano por fines, aunque no necesariamente por contenido, es la Ley General de Población que estuvo vigente desde 1974, por lo que resultaba ya insuficiente ante las realidades migratorias y al estar desfasada en relación con los compromisos internacionales adquiridos por México en materia de derechos humanos (Pérez, 2010: 186).

La LM consta de 162 artículos divididos en ocho títulos. El título primero que incluye cinco artículos contiene las «Disposiciones preliminares» que son el conjunto de principios en que se deberá sustentar la política migratoria, los conceptos que se utilizarán a lo largo de la ley, la precisión respecto a quién le corresponde su aplicación, así como la excepción que se puede hacer de la inspección migratoria a algunas personas extranjeras.

El título segundo, integrado por 12 artículos, desarrolla los «Derechos y obligaciones de los migrantes», enumerando y describiendo la forma en la cual deben ejercer y se deben respetar los derechos a las personas migrantes, especificando algunos de éstos, aunque se establece que contarán con todos los reconocidos en la Constitución y en los tratados, independientemente de su situación migratoria y, también, establece cuatro obligaciones generales de las cuales se pueden derivar otras más que deben cumplir las personas migrantes.

El título tercero incluye 13 artículos y está dedicado a «[L]as autoridades en materia migratoria» y establece las funciones que corresponden a la Secretaría de Gobernación (Segob), el Instituto Nacional de Migración (INM) y a otras secretarías que actúan como auxiliares en materia migratoria, y lo relativo a la profesionalización y certificación del personal del INM.

El título cuarto, compuesto por 35 artículos, se ocupa «Del movimiento internacional de personas y la estancia de extranjeros en el territorio nacional», estableciendo los requisitos de entrada y salida que se deben satisfacer, así como las nueve modalidades de estancia en las que puede estar una persona extranjera. El título quinto, que se integra por 11 artículos, desarrolla «[L]a protección a los migrantes que transitan por el territorio nacional», recogiendo una de las figuras más controvertidas de la ley: la presentación, que es 
como se le denomina a la detención que puede llevar a cabo la autoridad administrativa migratoria de personas que se encuentran en situación irregular, pero también incluye este título una serie de medidas y mínimos que las autoridades migratorias deben de cumplir para asistir, proteger, respetar y garantizar los derechos de las personas migrantes, principalmente cuando están en situaciones de vulnerabilidad o en situación migratoria irregular.

El título sexto, del artículo 77 al 137, es el más extenso de la ley al contener 60 artículos y se ocupa «Del procedimiento administrativo migratorio». En éste se recogen varios de los aspectos más controvertidos de la ley al ocuparse del control, verificación y revisión migratoria, así como de la presentación y alojamiento de extranjeros ${ }^{8}$ en las llamadas estaciones migratorias. También desarrolla lo relativo a la atención de personas en situación de vulnerabilidad (dedicado especialmente a la situación de niñas, niños y adolescentes no acompañados), el retorno asistido y la deportación de extranjeros que se encuentren irregularmente en México, así como todo lo relativo al «procedimiento administrativo migratorio de regulación migratoria» (sic).

El título séptimo, que se compone de 20 artículos, recoge lo relativo a "[L]as sanciones» que el INM puede imponer tanto a sus funcionarios como a personas físicas y morales, nacionales o extranjeras. Finalmente, el título octavo, integrado por cuatro artículos, desarrolla «[L]os delitos en materia migratoria», describiendo las conductas de tráfico, introducción, albergue o transporte de personas extranjeras sin documentación o autorización para estar en el país, sus agravantes y las obligaciones que en ello deben de cumplir el Ministerio Público de la Federación y el INM.

Si con la simple vigencia de la ley se cambiara la realidad que viven las personas migrantes en México, aun pese a lo que analizaré en los apartados siguientes, el balance de la Ley de Migración sería favorable, pues no se puede negar que contiene importantes avances en su texto al, por ejemplo, insistir en la importancia del respeto irrestricto de los derechos humanos de las personas migrantes sin importar su condición o situación migratoria y

${ }^{8}$ Así se le denomina en la lm a la privación de la libertad llevada a cabo por las autoridades administrativas migratorias. 
hacer énfasis en ello en diferentes partes de su contenido (artículos 1, 2, 6, 20, fracción VII; 22, 25, 28, fracción I; 30, fracción III; 67, 77, 101, 107, fracción V; 108, 112, 119, 123 y 143 de la LM), además de reconocer de manera expresa un conjunto de derechos y libertades con que cuenta toda persona migrante en territorio nacional (artículos 7 a 15 de la LM), por si quedaba alguna duda de que deben gozar de éstos por mandato constitucional y, no menos importante, establece sanciones para quien viole los derechos humanos de las personas migrantes (artículo 140, fracción VI de la LM).

Lo anterior, además de que los 12 principios que se establecen en el artículo 2 de la Lm como la base en la que debe sustentarse la política migratoria del Estado mexicano, de aplicarse y no convertirse sólo en letra que no llega a ser realidad, aportarían mucho pese a que algunos aspectos del contenido de éstos podrían tener una mayor visión desde el punto de vista de los derechos humanos y alejarse un poco más de la visión que vincula indisolublemente a la migración con la soberanía y la seguridad nacionales, ya que en la actualidad es necesario que exista un régimen internacional para la gobernanza de la migración que se centre sobre todo en los derechos humanos (Relator Especial, 2013: párr. 8).

Desgraciadamente, como más adelante lo confirmaremos, todos estos aspectos positivos, que en la letra buscan la protección de los derechos humanos de las personas migrantes, entran en contradicción con el propio contenido de algunas partes de la ley y, peor aún, a tres años de vigencia de ésta, la práctica y la realidad distan mucho de estar materializando esos aspectos positivos que contiene la Ley de Migración.

En este sentido, si bien es cierto que el problema de la incongruencia y contradicción que se da entre lo que dicen las normas jurídicas y la realidad, así como dentro del contenido de una misma norma jurídica que por un lado reconoce derechos y artículos más adelante pasa por encima de ellos, no es exclusivo en México de la LM, sino un problema evidente de nuestro sistema legal, en este caso se agrava por la poca visibilidad que se le da desde el derecho a la migración como un derecho humano.

El poco compromiso y seriedad con la que en México se ha tomado el contenido de la LM se demuestra de manera muy simple, como ya lo veíamos,

$156 \frac{\text { SEGUNDO SEMESTRE } 2014}{\text { MIGRACIÓN Y DESARROLLO NÚM. } 23}$ 
en primer lugar, desde su entrada en vigor por la inobservancia que se dio a las disposiciones transitorias de ésta al haberse emitido el Reglamento con un retraso de más de diez meses. Posteriormente, con el contenido que se le dio a dicho Reglamento, al extralimitarse en varios aspectos al contenido de la Lm sin que a nadie ello le causara extrañeza, pese a que todas las autoridades en el ámbito de sus competencias están obligadas a proteger, garantizar y respetar los derechos humanos. En tercer lugar, por el hecho de que pese a que la ley contiene varias erratas, ${ }^{9}$ al reformarse ésta en junio de 2013 , no se tuvo el cuidado ni la molestia de subsanarlo para dejar un contenido íntegro de la Ley de Migración; como tampoco se han actualizado las facultades de diversas dependencias a nivel federal para fomentar la promoción y protección de los derechos humanos de las personas migrantes (Guevara, 2011: 108); además, claro está, de las constantes violaciones que se dan a dicha ley y que son difíciles de demostrar en este documento, pero que basta con acudir a una oficina del INM, pasar por un puesto de verificación migratoria, visitar una estación migratoria o, simplemente, intentar entrar o salir de México siendo nacional o extranjero para darse cuenta de ello.

\section{¿Sólo inconstitucionalidades?}

La respuesta a la pregunta con la que inicio este apartado es: sí. Las razones de ello son muy simples. La primera, es que desde el 11 de junio de 2011 la Constitución mexicana establece en el primer párrafo del artículo 1o. que «todas las personas gozarán de los derechos humanos reconocidos en esta Constitución y en los tratados internacionales de los que el Estado Mexicano sea parte...». Eso significa que además de observar el contenido del texto

9 Véase, por ejemplo, la fracción XI del artículo 3 que dice: "[...] a quien pasea la calidad de mexicano [...]». Cuando debería decir: «posea». O bien, en los propios principios rectores en los que se habla de «[...] la observancia de las garantías individuales [...]», cuando éstas ya no existen y lo correcto es hablar de derechos humanos. Pero también el párrafo segundo, de la fracción II, del artículo 107 que dice: «[...] tratamiento médico que se haya; prescrito al alojado [...]», en donde evidentemente sobra el punto y coma que hay entre "haya» $\mathrm{y}$ "prescrito». Por sólo mencionar algunas de las más evidentes. 
constitucional en sentido estricto, cuando se hable de derechos humanos en México, necesariamente se tiene que voltear a ver el conjunto de tratados que en esa materia ha ratificado o se ha adherido el Estado mexicano. Que, contrario a lo que ocurría hasta antes de esa fecha, ahora existen reconocidos ciertos derechos humanos independientemente de que estén expresamente contenidos en el texto de los 136 artículos que conforman la Constitución, por estar comprendidos en un tratado del que México es parte. Significa de manera simple que el derecho de origen nacional y el derecho de origen internacional son ya, sin excusa ni limitación, alguna fuente directa de derechos humanos en México, sustento de atribuciones y protección con los que debe contar toda persona en razón de su naturaleza humana (Castilla, 2011: 144).

Todo lo anterior, de manera práctica, se traduce en que el catálogo de derechos humanos ya no se circunscribe como tradicional y de manera cerrada se hacía a los 29 artículos que integran el Título Primero de la Constitución, sino que a los derechos humanos contenidos ahí y en otras partes del texto constitucional hay que sumar los 26 derechos contenidos en la Convención Americana sobre Derechos Humanos, los 27 derechos contenidos en el Pacto Internacional de Derechos Civiles y Políticos, los cuatro derechos reconocidos en la Convención Interamericana para Prevenir, Sancionar y Erradicar la Violencia contra la Mujer, los 15 derechos contenidos en el Pacto Internacional de Derechos Económicos, Sociales y Culturales, los 41 derechos reconocidos en la Convención sobre los Derechos del Niño, los 29 derechos contenidos en la Convención sobre los Derechos de las Personas con Discapacidad, los 10 derechos contenidos en el Convenio sobre la Libertad Sindical y la Protección del Derecho de Sindicación, entre otros tantos más (Castilla, 2011: 144).

De esta manera, los derechos humanos son el género y los derechos de fuente constitucional e internacional sus especies, al haber creado el órgano de reformas a la Constitución un bloque constitucional de derechos humanos, un conjunto normativo de jerarquía suprema a partir del cual deberá determinarse la validez de la totalidad de las normas jurídicas distintas a la Constitución y a los tratados.

$158 \frac{\text { SEGUNDO SEMESTRE } 2014}{\text { MIGRACIÓN Y DESARROLLO NÚM. } 23}$ 
Así, el bloque de derechos humanos contenido en el primer párrafo del artículo 1o. constitucional implica en esencia que la Constitución en materia de derechos humanos está integrada por normas dispersas en otros conjuntos normativos (tratados). De esa manera, la Constitución mexicana, al referirse a derechos humanos, se conforma por dos cuerpos normativos: i) los contenidos en la conocida como Constitución - Constitución stricto sensu-, y ii) los contenidos en los tratados de los que México es parte - Constitución lato sensu.

Entendido lo anterior, en México no requerimos hacer ningún tipo de control de convencionalidad, pues al estar integrados los tratados al bloque constitucional de derechos humanos a la Constitución, lo que ahora en todo caso se deberá hacer es un control de constitucionalidad que, contrario a lo que antes pasaba y con base en lo que antes he señalado, ahora sí se autoriza constitucionalmente que los derechos contenidos en los tratados sean aplicados preferentemente, incluso a las normas que integran la Constitución stricto sensu. ${ }^{10} \mathrm{O}$ bien, si se le quiere ver de otra forma, lo que suele denominarse como control de convencionalidad ha sido constitucionalizado y más que eso, por el contenido del artículo 1o., los tratados ahora sí pueden estar por encima de la Constitución en la aplicación del principio pro persona, porque son Constitución y no existe jerarquía entre las normas que conforman ésta; ${ }^{11}$ tal y como también lo ha entendido la Corte Interamericana de Derechos Humanos al señalar que el control de constitucionalidad implica necesariamente un control de convencionalidad (Caso Gelman, 2013: párr. 88).

La segunda razón que sustenta mi afirmación inicial está estrechamente vinculada con lo antes señalado, ya que los jueces nacionales, en el momento

${ }^{10}$ Esto sin olvidar la limitada interpretación que hizo el Pleno de la Suprema Corte de Justicia de la Nación al resolver la contradicción de tesis 293/2011, el 3 de septiembre de 2013, en la que estableció que tratándose de restricciones prevalecerá la Constitución. Posición que no comparto al desnaturalizar el principio pro persona reconocido también constitucionalmente. En este sentido, véase CT-293/2011: Contradicción hecha tesis, disponible en http://justiciahable.org/justicia-y-derechos-humanos-bajo-fuego-amigo-ct-2932011-contradiccion-hecha-tesis/

${ }^{11}$ Véase como referencia de esa afirmación: Suprema Corte de Justicia de la Nación, tesis aislada XXXIX/90 (8a.), cuyo rubro es: "Constitución, todas sus normas tienen la misma jerarquía y ninguna de ellas puede declararse inconstitucional». 
en el que aplican el derecho de origen internacional, no pueden declarar la inconvencionalidad de una norma de origen nacional, pues ello sólo lo puede hacer un órgano internacional, pese a lo que de manera poco seria y desnaturalizando el verdadero significado, fines y contenido del control de convencionalidad han difundido ampliamente la Corte Interamericana de Derechos Humanos, la Suprema Corte de Justicia de la Nación y un amplio sector de la doctrina (Castilla, 2013: 51-97). Esto es así porque un efecto inmediato de determinar que una norma o acto nacional viola una obligación internacional contenida en un tratado es la determinación de la responsabilidad internacional, situación que nunca va a poder llevar a cabo un juez nacional (Fix-Zamudio, 2013), cuando éstos pueden ser también generadores de dicha responsabilidad internacional como parte de los órganos del Estado que son.

Lo que de manera generalizada por repetición más que por reflexión y análisis serio suele llamarse control de convencionalidad es más bien el ejercicio de la garantía de tratados o, como lo ha entendido más recientemente la Corte Interamericana, sin reconocer su desaseo en el uso de ese término jurídico, que lo que ésta llama control de convencionalidad es una mera aplicación del derecho internacional (Caso Gelman, 2013: párr. 68). De esa forma, esa aplicación del derecho internacional o, mejor dicho, puesta en práctica de la garantía de tratados, hace evidente que sólo es necesario hacer una revisión de la constitucionalidad, pues en ello, al utilizarse el bloque constitucional de derechos humanos, ${ }^{12}$ necesariamente se utiliza este conjunto normativo (Constitución-tratados) para evaluar las leyes inferiores y ajenas a éste.

Por todo lo anterior, en este documento sólo me ocuparé de las posibles inconstitucionalidades, pues, insisto, al hacer ello, analizaré si la Ley de Migración es contraria al bloque constitucional de derechos humanos que está integrado por las normas que reconocen derechos humanos contenidas tanto en la Constitución como en los tratados, tal y como lo dispone el artículo 1 o. constitucional.

${ }^{12}$ La Suprema Corte de Justicia de la Nación, al resolver la contradicción de tesis 293/2011 a lo que yo denomino bloque constitucional de derechos humanos, ella denomina «parámetro de regularidad constitucional». Sin embargo, yo prefiero mantener la denominación propia, en razón de que el máximo tribunal del país con ese término creó una jerarquía de normas donde no debía haberla.

$160 \frac{\text { SEGUNDO SEMESTRE } 2014}{\text { MIGRACIÓN Y DESARROLLO NÚM. } 23}$ 


\section{Inconstitucionalidades desde La Ley de Migración mexicana}

Sostener la compatibilidad de las leyes de migración o extranjería con los derechos humanos no es fácil $y$, siendo estrictos, prácticamente ninguna podría soportar dicha evaluación si se analiza con seriedad el derecho a migrar en conjunto con el principio de igualdad reconocido en prácticamente todos los ordenamientos constitucionales y tratados de derechos humanos. En realidad, si han surgido y se sostienen leyes de ese tipo es porque se encuentran amparadas en ese difuso constructo humano llamado soberanía de los Estados, que les autoriza a regular la migración y, con base en ello, se ha legitimado de manera muy dudosa la creación y aplicación discriminatoria (en razón de la nacionalidad) de leyes migratorias.

De igual forma, si la migración se analizara como el derecho humano que es y no como un aspecto de seguridad nacional, de intercambio de fuerza laboral o como elemento de desarrollo, sería más fácil de regular y también impediría que existieran leyes, como muchas de las actualmente vigentes, que se extralimitan en las restricciones a los derechos humanos de las personas migrantes amparadas en los aspectos antes señalados, al presumir que quien ejerce su derecho a migrar es un peligro, una carga o un factor de desestabilización. Es decir, sólo se ve a la persona migrante como mano de obra, variable para el desarrollo o fuente de criminalidad, pero no como ser humano.

Así por ejemplo, si en México consideramos que el derecho a migrar está reconocido en el artículo 11 de la Constitución que establece: ${ }^{13}$ "Toda persona tiene derecho para entrar en la República, salir de ella, viajar por su territorio y mudar de residencia, sin necesidad de carta de seguridad, pasaporte, salvoconducto u otros requisitos semejantes»; y que, como restricciones a ese derecho, el referido artículo establece: «El ejercicio de este derecho estará subordinado a las facultades de la autoridad judicial, en los casos de

\footnotetext{
${ }^{13}$ En este documento no se cita, ni analizará, el segundo párrafo del artículo 11 de la Constitución, ya que ello implicaría revisar también la Ley sobre Refugiados y Protección Complementaria, publicada en el Diario Oficial de la Federación el 27 de enero de 2011, lo cual, sobrepasa los objetivos de este análisis.
} 
responsabilidad criminal o civil, y a las de la autoridad administrativa, por lo que toca a las limitaciones que impongan las leyes sobre emigración, inmigración y salubridad general de la República, o sobre extranjeros perniciosos residentes en el país»; resulta evidente que muchos aspectos de la Ley de Migración serían inconstitucionales al ir más allá de lo que establece en esta materia la Constitución.

Sin embargo, se sostiene y no se pone en duda su constitucionalidad, porque todo aquello que sobrepasa la regulación del entrar (ingreso dice la LM), salir, viajar (tránsito dice la LM) y mudar de residencia (estancia dice la LM), encuentra respaldo en la "preservación de la soberanía y de la seguridad nacionales» como lo establece la Ley de Migración, ${ }^{14}$ pese a que constitucionalmente no estén vinculados, ni puedan ser tomados como una variable de restricción válida de esas cuatro acciones, pues, en todo caso, la idea de «extranjeros perniciosos» como razón de limitación del derecho sólo está dirigida a quienes tengan esa condición y sean "residentes en el país», nunca respecto a la salida, entrada o tránsito. Además de que, no podemos calificar a priori como perniciosos a los extranjeros sin estar cometiendo un acto de discriminación en razón de la nacionalidad prohibido por el párrafo quinto del artículo 1o. constitucional, como tal parece lo hacen las leyes migratorias al vincular esta materia con la seguridad nacional, la seguridad pública y la preservación de la soberanía, más allá de lo necesario y sobrepasando la medida indispensable en una sociedad democrática.

Los intereses aparentes en materia de seguridad suelen superar las consideraciones de los derechos humanos por parte de los Estados, a pesar de que la abrumadora mayoría de los migrantes, incluidos los que cruzan las fronteras de forma irregular, no suponen ninguna amenaza para la seguridad (A/68/283 2013: 19).

\footnotetext{
${ }^{14}$ Aunque también, debo señalarlo, las limitaciones a estos derechos basadas en temas de seguridad nacional, seguridad, salud u orden públicos, encuentran respaldo legal en el artículo 22.3 de la Convención Americana sobre Derechos Humanos (CADH) y el artículo 12.3 del Pacto Internacional de Derechos Civiles y Políticos (PIDCP).
}

$162 \frac{\text { SEGUNDO SEMESTRE } 2014}{\text { MIGRACIÓN Y DESARROLLO NÚM. } 23}$ 
Lo anterior se explica de mejor manera si tomamos en cuenta que toda persona tiene derecho a ${ }^{15}$ entrar en la República [mexicana]; ${ }^{16}$ salir de ella; ${ }^{17}$ viajar (circular) por su territorio, ${ }^{18} \mathrm{y}$ mudar de residencia. ${ }^{19}$ Esto, sin necesidad de carta de seguridad, pasaporte, salvoconducto u otros requisitos semejantes; y que el ejercicio de este derecho estará subordinado a las facultades de la autoridad judicial, en los casos de responsabilidad criminal o civil; y las [facultades] de la autoridad administrativa, por lo que toca a las limitaciones que impongan las leyes sobre emigración, inmigración y salubridad general de la República, o [las limitaciones] sobre extranjeros perniciosos residentes en el país.

De lo anterior, podemos entender que la Ley de Migración, al estar dirigida a la autoridad administrativa y ser esa ley sobre emigración e inmigración a la que se refiere la Constitución, sólo puede: a) limitar el derecho de entrar (ingreso), salir, viajar (tránsito-circulación) y mudar de residencia (estancia), y b) limitar los derechos de los extranjeros perniciosos residentes en México.

Con lo cual, todo lo que exceda a ello, es inconstitucional. Por lo que, atendiendo a este análisis, serían inconstitucionales, por citar algunos ejemplos, en todo o en parte al menos, los artículos: 3, fracciones VIII, X, XX y XXX; 16, 17, 18, fracciones II y III; 20, fracciones V y VII; 33, 35, 36, 37, 68, 69, $80,81,92,93,94,95,97,99,100,106,107,108,109,110,111,121,124,138$, 144, 149, 150, 153, 154, 155, 158, 159, 160, 161 y 162 de la Ley de Migración. Muchas de estas normas por limitar con su aplicación otros derechos humanos distintos a los que aquí se han referido, otras por ocuparse de temas que

${ }^{15}$ En este primer análisis se utiliza en aplicación del principio pro persona reconocido constitucionalmente, sólo el artículo 11 de la Constitución, dejando de lado los artículos 22 (derecho de circulación y de residencia) de la Convención Americana sobre Derechos Humanos (CADH) y 12 (derecho de circulación y de residencia) del Pacto Internacional de Derechos Civiles y Políticos (PIDCP), al establecer el texto constitucional mexicano una mejor protección de la persona señalando que este derecho lo tiene "toda persona», en tanto que ambos tratados establecen que el derecho lo tiene «toda persona que se halle legalmente en el territorio de un Estado».

${ }^{16}$ En parte, este derecho también está reconocido en el artículo 22.5 de la CADH y 12.4 del PIDCP.

${ }^{17}$ Este derecho también está reconocido en el artículo 22.2 de la CADH y 12.2 del PIDCP.

${ }^{18}$ En parte, este derecho también está reconocido en el artículo 22.1 de la CADH y 12.1 del PIDCP. ${ }^{19} \mathrm{Idem}$. 
van más allá de las facultades de la autoridad administrativa migratoria y unas más, como las últimas que se mencionan, por ser de naturaleza estrictamente penal que por ninguna razón deberían estar incluidas en una ley de naturaleza administrativa.

No obstante, al autorizarse incluso por tratados de derechos humanos como la Convención Americana sobre Derechos Humanos (artículo 22 -derecho de circulación y de residencia-) y el Pacto Internacional de Derechos Civiles y Políticos (artículo 12 - derecho de circulación y de residencia-) la restricción a los derechos de salir, circular y residir en un país para prevenir infracciones penales o para proteger la seguridad nacional, la seguridad o el orden públicos, la moral o la salud públicas o los derechos y libertades de los demás, se reduce el número de artículos o porciones normativas de la Ley de Migración que podrían considerarse como inconstitucionales, ya que muchas de éstas resulta fácil incluirlas en los supuestos tan amplios que pueden incluirse en, por ejemplo, orden público, seguridad nacional, prevenir infracciones penales o proteger los derechos de terceros. ${ }^{20}$

Pero, aún con esa posibilidad que abre la Convención Americana sobre Derechos Humanos (CADH) y el Pacto Internacional de Derechos Civiles y Políticos (PIDCP), no podemos olvidar que estas restricciones, de acuerdo con esos mismos tratados de derechos humanos, deben estar previstas en ley, ser necesarias, aplicarse en la medida indispensable en una sociedad democrática (proporcionalidad) y ser compatibles con los demás derechos reconocidos en dichos tratados; por lo que no toda restricción podría considerarse válida, no todas las normas de la LM serían compatibles con el bloque constitucional de derechos humanos.

Paradójicamente, este aspecto es en uno de los pocos en los cuales el criterio que estableció la Suprema Corte de Justicia de la Nación, al resolver la contradicción de tesis 293/2011, sería útil pensando en una revisión a profun-

${ }^{20}$ Advierto que esta afirmación la hago sólo con el fin de poder hacer un mayor análisis de toda la LM, pues si atendemos al texto del artículo 1o. constitucional y además aplicamos el principio pro persona, el análisis concluiría como antes lo señalé, ya que en este caso las restricciones admisibles por los tratados se deberían de ignorar y únicamente se debería aplicar la norma constitucional que es la que autoriza una menor restricción o menos posibilidades de restricción de los derechos humanos.

$164 \frac{\text { SEGUNDO SEMESTRE } 2014}{\text { MIGRACIÓN Y DESARROLLO NÚM. } 23}$ 
didad de diversas normas de la Ley de Migración, pues en ésta se estableció que cuando haya una restricción expresa en la Constitución al ejercicio de los derechos humanos, se deberá estar a lo que indica la norma constitucional. Aunque en este caso también una aplicación correcta del principio pro persona (Castilla, 2009: 65-83) debería llevar a la misma conclusión, esto es, a considerar que la norma integrante del bloque constitucional de derechos humanos que menos restringe éstos es en dicho supuesto de manera clara la norma constitucional (artículo 11) frente a las normas de tratados $(22 \mathrm{CADH}$ y 12 PIDCP).

Con este entendido, volvemos a lo establecido párrafos antes para concluir que un gran número de normas de la Ley de Migración son contrarias a la Constitución, por lo que deberían ser expulsadas del sistema jurídico mexicano. Esta opción debe ser explorada por quienes nos dedicamos a la defensa de los derechos de las personas migrantes, pues aunque parezca complicada, tiene amplias posibilidades para argumentarse. Aunque también la justificación vaga y ambigua de la seguridad nacional, como elemento necesariamente vinculado a la migración, según se afirma por muchas personas, dificulta la declaración de inconstitucionalidad de algunas normas de la LM citadas. Por la forma en la cual se ha construido el sistema normativo de la migración, parece que atacar la presunción de constitucionalidad de la LM no es una labor sencilla.

No obstante, existen normas y porciones normativas de la Ley de Migración que resultan inconstitucionales más allá del contenido del artículo 11 constitucional, así como por el análisis sistemático de éste con otras normas constitucionales y de tratados. Por ello, a continuación estableceré algunas de las más evidentes, respecto a las cuales, desde ya, debe buscarse que sean expulsadas del sistema jurídico mexicano por ser contrarias al bloque constitucional de derechos humanos. Para facilitar el análisis, dividiré en cuatro grupos los ejemplos más claros de inconstitucionalidad que contiene la Ley de Migración. El primero mostrará algunas normas que contravienen directamente al artículo 11 constitucional. El segundo, aquellas que son contrarias a la presunción de inocencia y que afectan el derecho a migrar. En tercer lugar, algunas normas que afectan la libertad personal al extralimitarse de lo 
constitucional e internacionalmente autorizado. Finalmente, aquellas que afectan el derecho a la protección judicial o el acceso a la justicia.

Si bien podrían configurarse y existen algunas inconstitucionalidades más, ésas requieren de mayor análisis desde otros ámbitos del derecho. Asumiendo el riesgo de parecer poco profundo, en esta ocasión sólo desarrollaré las que considero las inconstitucionalidades más ilustrativas de la lamentable situación que presenta la regulación de la migración en México.

Restricciones inconstitucionales por no estar previstas en ley

En el primer grupo se puede citar el artículo 7 de la Ley de Migración, el cual establece: "La libertad de toda persona para ingresar, permanecer, transitar y salir del territorio nacional tendrá las limitaciones establecidas en la Constitución, los tratados y convenios internacionales de los cuales sea parte el Estado mexicano, esta Ley y demás disposiciones jurídicas aplicables». Resulta inconstitucional por ser contrario al artículo 11 de la Constitución, así como a los artículos 22.3 de la CADH y 12.3 del PIDCP, la porción normativa: «y demás disposiciones jurídicas aplicables». Esto en razón de que toda restricción a los derechos a ingresar, permanecer, transitar y salir del país, de acuerdo con las normas integrantes del bloque constitucional de derechos humanos, como antes ya se desarrolló, debe estar establecida en ley. Al no precisarse en esta parte del referido artículo 7 cuáles son esas «disposiciones jurídicas aplicables», la norma deja a la discrecionalidad de quien la aplique e interprete, determinar cuáles son éstas y, por tanto, es contrario a lo ordenado constitucionalmente.

Si tomamos en cuenta que, de conformidad con la Constitución y los tratados de derechos humanos, el derecho a migrar compuesto por los derechos de entrar-ingresar, salir, transitar-circular y residir-cambiar de residencia, pueden ser restringidos sólo en supuestos específicos (seguridad nacional, orden público, derechos de terceros, responsabilidad criminal), la Ley de Migración debería enumerar de manera expresa las leyes que pueden contener esa restricción, pero no dejarlo de manera abierta, pues al hablar de

$166 \frac{\text { SEGUNDO SEMESTRE } 2014}{\text { MIGRACIÓN Y DESARROLLO NÚM. } 23}$ 
«disposiciones jurídicas», quien aplique e interprete dicho artículo podría entender como jurídicamente válidos reglamentos, circulares o cualquier otra disposición jurídica que no satisfaga el requisito de ser considerada una ley.

No debemos olvidar que para efectos de restricciones a los derechos humanos y, en este caso, por mandato expreso de los artículos 11 de la Constitución, 22.3 de la CADH y 12.3 del PIDCP, la restricción sólo puede estar establecida en ley. Y por ley debe entenderse aquella norma jurídica emanada del Poder Legislativo por el procedimiento previsto en la Constitución, esto es, ley en sentido formal y material (principio de reserva de ley) dictada en razón del interés general o público; ${ }^{21}$ o bien, como lo dice la Corte Interamericana: «significa norma jurídica de carácter general, ceñida al bien común, emanada de los órganos legislativos constitucionalmente previstos y democráticamente elegidos, y elaborada según el procedimiento establecido por las constituciones de los Estados parte para la formación de las leyes» (OC-6/86, 1986: párr. 38).

Además, si este análisis lo enmarcamos en el hecho de que la Ley de Migración, al estar dirigida a personas protegidas por el artículo 1o. constitucional, 1.1 de la CADH y 2.1 del PIDCP, entre otros, para que no sean discriminadas en razón de su nacionalidad, el escrutinio sobre dicha ley debe ser especialmente reforzado y estricto, pues no sólo se está salvaguardando un derecho humano concreto, sino también el principio de igualdad y no discriminación establecido en las normas del bloque constitucional de derechos humanos.

De esta manera, resulta evidente la inconstitucionalidad de la porción normativa "y demás disposiciones jurídicas aplicables». Expresión que también es utilizada con el fin de restringir el ejercicio de derechos humanos en los artículos 35 (entrar y salir del país), 36 (ingresar al territorio), 43 (internamiento regular y permanencia en territorio), 52 (permanecer en territorio nacional), 86 (abandonar el país), 128 (plazo de resolución de trámites

${ }^{21}$ Cfr. Suprema Corte de Justicia de la Nación, tesis jurisprudencial 1a./J. 2/2012 (9a.), de rubro: «Restricciones a los derechos fundamentales. Elementos que el juez constitucional debe tomar en cuenta para considerarlas válidas»; y Suprema Corte de Justicia de la Nación, tesis aislada 1a. CCXV/2013 (9a.), de rubro: "Derechos humanos. Requisitos para restringirlos o suspenderlos conforme a los artículos 1o. de la Constitución Política de los Estados Unidos Mexicanos y 30 de la Convención Americana sobre Derechos Humanos». 
migratorios) y 134 (solicitud de regulación migratoria) de la Ley de Migración, al menos.

Vulneración de la presunción de inocencia y el derecho a migrar

En el segundo grupo de artículos que van en contra del bloque constitucional de derechos humanos, se puede poner como ejemplo el artículo 43, fracción I, que establece:

Sin perjuicio de lo dispuesto en el artículo 42 de este ordenamiento, las autoridades migratorias podrán negar la expedición de la visa, la internación regular a territorio nacional o su permanencia a los extranjeros que se ubiquen en alguno de los siguientes supuestos: I. Estar sujeto a proceso penal o haber sido condenado por delito grave conforme a las leyes nacionales en materia penal o las disposiciones contenidas en los tratados y convenios internacionales[...].

En este caso, resulta inconstitucional la porción normativa «Estar sujeto a proceso penal». Esto, porque el artículo 20, apartado B, fracción I, de la Constitución, así como los artículos 8.2 de la CADH, 14.2 del PIDCP y 18.2 de la Convención Internacional sobre la Protección de los Derechos de todos los Trabajadores Migratorios y de sus Familiares (CIPDTMF), establecen que toda persona imputada, inculpada o acusada tiene derecho a que se presuma su inocencia mientras no se pruebe su culpabilidad de conformidad con la ley, mientras no se declare su responsabilidad mediante sentencia emitida por el juez de la causa.

En ese sentido, la negativa de expedición de visados, de autorizaciones de entrada, salida, tránsito y residencia de manera regular por el hecho de que una persona esté sujeta a un proceso penal, vulnera de manera evidente la presunción de inocencia. Esto es así porque no debemos olvidar que la presunción de inocencia comporta el derecho de toda persona a ser tratada como inocente en tanto no se declare su culpabilidad por virtud de una sentencia condenatoria, lo que implica que se debe impedir en la mayor

$168 \frac{\text { SEGUNDO SEMESTRE } 2014}{\text { MIGRACIÓN Y DESARROLLO NÚM. } 23}$ 
medida posible la aplicación de medidas que impliquen una equiparación de hecho entre imputado y culpable, es decir, conlleva la prohibición de cualquier tipo de resolución que suponga la anticipación de la pena..$^{22}$

Entiendo que esa prohibición pueda encontrar justificación en aspectos relacionados con las amplísimas expresiones «seguridad nacional» $\mathrm{u}$ «orden público». También que podría tener como fin, por una parte, evitar que la persona se pudiera extraer de la acción de la justicia o bien, evitar que una persona que podría tener antecedentes penales ingrese, salga, transite o resida en el país. Sin embargo, siendo esos los posibles fines de la restricción, resulta desproporcional y poco efectiva la restricción que se impone.

Esto es así porque si el otorgamiento de visados y la autorización de entrada, salida, residencia y tránsito que contempla la Ley de Migración, tienen como fin saber con precisión quién está en el país, la mejor forma de hacerlo es justamente por los causes legales que ésta establece, pues de otra forma, si en verdad la persona quiere extraerse de la acción de la justicia, dudo mucho que busque hacerlo por las vías legales, si siempre tendrá la posibilidad de hacerlo de manera irregular; además de que se podrían implementar otro tipo de medidas para mantener contacto con la persona vinculada a un proceso penal que no fueran adelantadamente restrictivas de sus derechos humanos, a la vez que se asegura tener certeza respecto al lugar en el que podrá ser ubicada.

No obstante, la Ley de Migración, como otras tantas en el mundo, prefiere criminalizar a priori a las personas que pretenden o han ejercido su derecho a migrar, pues de esa forma las autoridades justifican de manera adelantada la incapacidad que tienen para desempeñar sus funciones, difundiendo entre los ciudadanos que todos los males de un país son consecuencia de la inmigración.

Si como ya he establecido antes, toda restricción a los derechos humanos debe ser admisible en el ámbito constitucional (establecida en ley), necesaria en una sociedad democrática (idónea para el objeto y fin) y proporcional (no

${ }^{22}$ Cfr. Suprema Corte de Justicia de la Nación, tesis aislada: 1a. XCIV/2013 (10a.), de rubro: «Presunción de inocencia en su vertiente de regla de trato procesal». 
puede hacerse a costa de una afectación innecesaria o desmedida a otros bienes y derechos constitucionalmente protegidos), resulta evidente que la porción normativa «estar sujeto a un proceso penal» utilizada en la Ley de Migración, resulta desproporcional y, por tanto, inconstitucional al afectar la presunción de inocencia protegida en el bloque constitucional de derechos humanos (artículos 20, A, fracción I, constitucional, 8.2 de la CADH, 14.2 del PIDCP y 18.2 de la CIPDTMF), al existir otras formas menos lesivas que podrían implementarse y no la negativa total del ejercicio de los derechos vinculados con el derecho a migrar y la eliminación de la presunción de inocencia de manera simultánea; con lo que es doblemente grave y cuestionable.

De esta manera, resulta evidente la inconstitucionalidad de la porción normativa «estar sujeto a proceso penal». Expresión que también es utilizada con el fin de restringir el ejercicio de derechos humanos en los artículos 43, fracción I (internación regular y permanencia en territorio), 64, fracción VI (condición de residente temporal o permanente), y 144, fracción IV (permanencia en el país/deportación), de la Ley de Migración, al menos.

\section{Vulneración de la libertad personal}

El tercer grupo de evidentes vulneraciones de los derechos humanos reconocidos en el bloque constitucional está relacionado con lo que en la Ley de Migración se denomina presentación y alojamiento que en realidad, y sin simulaciones lingüísticas legales, son la detención y privación de la libertad llevada a cabo por la autoridad administrativa migratoria, en específico, por el INM.

Si bien la detención misma de una persona migrante por estar en situación irregular es muy cuestionable, así como su «presentación» hasta por 36 horas, en este breve análisis sólo centraré mi atención en el llamado "alojamiento», que es la más grave y evidente violación del derecho a la libertad personal. ${ }^{23}$ En ese sentido, el artículo 111 de la Ley de Migración, establece:

${ }^{23}$ Sin que por ello dejen de ser graves y requieran un análisis a profundidad de su constitucionalidad dicha "presentación", así como el establecimiento de retenes migratorios, la implementación

$170 \frac{\text { SEGUNDO SEMESTRE } 2014}{\text { MIGRACIÓN Y DESARROLLO NÚM. } 23}$ 
El Instituto resolverá la situación regular de los extranjeros presentados en un plazo no mayor de 15 días hábiles, contados a partir de su presentación. El alojamiento en las estaciones migratorias únicamente podrá exceder de los 15 días hábiles a que se refiere el párrafo anterior cuando se actualicen cualquiera de los siguientes supuestos: [...] En los supuestos de las fracciones I, II, III y IV de este artículo el alojamiento de los extranjeros en las estaciones migratorias no podrá exceder de 60 días hábiles.

Esto significa que una persona que se encuentra en situación irregular, de acuerdo con la norma antes citada, puede ser privada de la libertad en una estación migratoria entre 15 y 60 días hábiles. ${ }^{24}$ Ello podría parecer normal, con sus respectivas reservas, si el estar en situación irregular en México fuese un delito. Pero no lo es.

En México hay 32 estaciones migratorias, 15 estancias provisionales tipo A previstas para una estancia máxima de 48 horas y 12 estaciones provisionales tipo B para una estadía máxima de 7 días. Además de que se pueden habilitar otros lugares con la misma finalidad (Sin Fronteras, 2014: 15).

De esta manera, dicha privación de libertad es de carácter eminentemente administrativo y ahí es donde está la inconstitucionalidad, pues si leemos el tercer párrafo del artículo 21 constitucional, podemos ver que la autoridad administrativa sólo está facultada para privar de la libertad por medio de la figura del arresto, y éste sólo puede aplicarse hasta por 36 horas. En tanto

de operativos de revisión de documentos y las solicitudes de identificación dentro del territorio nacional de personas a partir de su perfil físico o manera de hablar, pues dichos actos también podrían dar lugar a privaciones arbitrarias de libertad. Por espacio aquí no las desarrollo, pero deben ser escrupulosamente revisadas al, en mi opinión, exceder esos actos los límites que impone el bloque constitucional de derechos humanos.

${ }^{24}$ De conformidad con la Estadística Migratoria del INM, sin especificarse el tiempo de privación de libertad, en el año 2011 hubo 63,072 personas «alojadas» en estaciones migratorias, para 2012 se privó de la libertad a 85,100 personas. En 2013 y lo que va de 2014 ya no hay cifras precisas de ello, ya que en la estadística se habla de «extranjeros presentados ante autoridad migratoria" y en esa cifra se incluye a las personas ingresadas en estaciones migratorias y otros supuestos. Con esa reserva, en 2013 hubo 86,929 «eventos». Todas esas cifras incluyen hombres, mujeres, niños y niñas con muy variadas condiciones personales y diversidad. 
que el segundo párrafo del artículo 14 constitucional establece que nadie puede ser privado de la libertad sino mediante juicio seguido ante los tribunales previamente establecidos, en el que se cumplan las formalidades esenciales del procedimiento y conforme a las leyes expedidas con anterioridad al hecho. Además de que el artículo 16 constitucional en sus párrafos cuarto, quinto, sexto, séptimo, octavo y décimo ordenan que en materia penal, como máximo poder sancionador del Estado, las autoridades que detengan o priven de la libertad a una persona, la deben de poner a disposición de un juez para que éste determine la legalidad de la detención. Y más aún, el artículo 18 constitucional, en su primer párrafo, sólo autoriza la prisión preventiva en los casos de que se haya cometido un delito que merezca pena privativa de la libertad, además de que el artículo 19 de la misma Constitución establece que ninguna detención ante autoridad judicial puede exceder de 72 horas, y que la prisión preventiva sólo procede cuando otras medidas cautelares no sean suficientes para garantizar la comparecencia del imputado en materia penal; insisto, todos estos últimos artículos en ejercicio de máximo poder sancionador del Estado, nunca en materia administrativa.

En tanto que los tratados que reconocen derechos humanos y que en este documento hemos establecido como referente, sin ser los únicos que se podrían analizar, establecen que nadie puede ser privado de su libertad física, salvo por las causas y en las condiciones fijadas de antemano por las Constituciones Políticas de los Estados parte o por las leyes dictadas conforme a ellas y con arreglo al procedimiento establecido en éstas (artículo 7.1 de la CADH y 9.1 del PIDCP); además de que toda persona detenida o retenida debe ser llevada, sin demora, ante un juez u otro funcionario autorizado por la ley para ejercer funciones judiciales y tendrá derecho a ser juzgada dentro de un plazo razonable o a ser puesta en libertad, sin perjuicio de que continúe el proceso; por lo que la prisión preventiva de las personas que hayan de ser juzgadas no debe ser la regla general, pero su libertad podrá estar subordinada a garantías que aseguren la comparecencia del acusado en el acto del juicio, o en cualquier momento de las diligencias procesales $y$, en su caso, para la ejecución del fallo (7.3 de la CADH y 9.3 del PIDCP).

$172 \frac{\text { SEGUNDO SEMESTRE } 2014}{\text { MIGRACIÓN Y DESARROLLO NÚM. } 23}$ 
En tanto que si bien el artículo 17 de la CIPDTMF autoriza la detención de los trabajadores migratorios por violación de las disposiciones sobre migración, dicho artículo exige (17.7) que éstos gocen de los mismos derechos que los nacionales del Estado en el que se encuentren en igual situación, es decir, que hubiesen cometido una infracción a una ley de naturaleza administrativa. Lo que significa que pese a dicha autorización, la Convención sobre Trabajadores Migratorios remite nuevamente a las leyes que resulten aplicables para todos los nacionales del país.

De esa forma, parece evidente que la "presentación» y posterior «alojamiento» de las personas migrantes en situación irregular es inconstitucional, ya que, por infracciones administrativas, el máximo de privación de libertad autorizado constitucionalmente (arresto) es de 36 horas; ${ }^{25}$ la prisión preventiva sólo es admisible en materia penal bajo concretas condiciones y, en todo caso, es determinada por un juez competente; toda persona detenida o retenida debe ser llevada, sin demora, ante un juez u otro funcionario autorizado por la ley para ejercer funciones judiciales con el fin de que revise la legalidad de la detención; toda privación de libertad, pero principalmente las superiores a 36 horas, deben ser determinadas por una autoridad jurisdiccional; el INM es una autoridad administrativa y no tiene autorizado ejercer funciones judiciales; la libertad personal no es uno de los derechos que las normas integrantes del bloque constitucional de derechos humanos autorizan para que a priori sean restringidos a las personas extranjeras. ${ }^{26}$

Bajo esta perspectiva, resulta por demás claro que el artículo 111 de la Ley de Migración, al igual que los artículos 68, en relación con los artículos 3, fracción XX; 20, fracción VII; 69, 99, 100, 101, 105, 106, 109, 112, fracción II;

${ }^{25}$ Cfr. Suprema Corte de Justicia de la Nación, tesis aislada: 2a./J. 117/2007 (9a.), de rubro: «Alcoholímetro. El artículo 102, párrafo primero, del Reglamento de Tránsito para el Distrito Federal no viola el artículo 21 constitucional».

${ }^{26}$ Tanto en la Constitución mexicana como en diversos tratados de derechos humanos, sólo algunos derechos políticos están expresamente limitados para su ejercicio a los extranjeros. Esto no significa que los demás derechos humanos no se puedan restringir a las personas extranjeras, sin embargo, de hacerse deben cumplirse los estrictos requisitos de toda restricción a los derechos humanos más el especial énfasis que se debe hacer en que la medida no sea discriminatoria en razón de la nacionalidad. 
118, último párrafo; todos de la misma ley, al menos son inconstitucionales por vulnerar el derecho a la libertad personal garantizado por diversas normas integrantes del bloque constitucional de derechos humanos.

Como lo he advertido en los apartados anteriores y lo reitero ahora, las personas migrantes tienen una restricción o modulación del ejercicio de su derecho a entrar en el país, además de algunas restricciones expresas al ejercicio de sus derechos políticos contenidas tanto en la Constitución como en los tratados, pero el resto de derechos humanos les deben ser respetados y garantizados sin discriminación, y en la misma medida que a cualquier persona mexicana. Toda restricción a sus derechos debe superar el test de proporcionalidad y el de igualdad. Por lo que, sin duda alguna, se muestra de forma evidente que la privación de libertad que autoriza la Ley de Migración a las personas migrantes en situación irregular es también una clara contravención al principio de igualdad, pues se está aplicando una medida privativa de la libertad en razón del origen nacional de las personas. Situación muy grave que no debería estar permitida por parte de los jueces federales mexicanos de todos los niveles; como he señalado, la revisión de la LM debe hacerse de forma reforzada al implicar no sólo el análisis de una norma específica que pudiera demandarse, sino también de manera permanente el deber de asegurar el principio de no discriminación.

\section{Vulneración del acceso efectivo a la justicia}

Para el cuarto grupo de artículos de la Ley de Migración, que resultan inconstitucionales por afectar el derecho al acceso a la justicia efectivo, utilizo como ejemplo uno de los más flagrantes y que está relacionado con lo analizado en el apartado anterior. Por ello, nuevamente hago referencia al artículo 111, que establece el eufemísticamente llamado alojamiento y que, como uno de los supuestos en los que autoriza que éste exceda de los 15 días hábiles y, por tanto, pueda llegar hasta los 60 días hábiles, es: «V. Que se haya interpuesto un recurso administrativo o judicial en que se reclamen cuestiones inherentes a su situación migratoria en territorio nacional; o se haya

$174 \frac{\text { SEGUNDO SEMESTRE } 2014}{\text { MIGRACIÓN Y DESARROLLO NÚM. } 23}$ 
interpuesto un juicio de amparo y exista una prohibición expresa de la autoridad competente para que el extranjero pueda ser trasladado o para que pueda abandonar el país». Es decir, que si la persona migrante quiere que un juez evalúe la legalidad de su detención o cualquier situación relacionada con su situación migratoria, eso es motivo suficiente para que la persona pueda estar más de 15 días hábiles privada de libertad. Con lo cual se condiciona la posibilidad de no ser privado de la libertad por más de 15 días hábiles al hecho de que no se busque obtener acceso a la justicia, que no se promueva ninguna acción o recurso para la defensa de sus derechos. Parece evidente que por donde se le vea es contrario a las normas integrantes del bloque constitucional de derechos humanos.

En el caso de haber dudas, se puede señalar que ni en el artículo 17 constitucional (acceso a la justicia), como tampoco en los artículos 8.1 (garantías judiciales) y 25 (protección judicial) de la CADH, 2.3 y 14.1 del PIDCP, 16.8 y 18.1 de la CIPDTMF, cabe la posibilidad de que una condición para la defensa de los derechos humanos sea la amenaza de continuar o ser privado de la libertad, pues incluso el referido artículo 16.8 de la CIPDTMF establece de manera expresa que:

Los trabajadores migratorios y sus familiares que sean privados de su libertad por detención o prisión tendrán derecho a incoar procedimientos ante un tribunal, a fin de que éste pueda decidir sin demora acerca de la legalidad de su detención y ordenar su libertad si la detención no fuere legal. En el ejercicio de este recurso, recibirán la asistencia, gratuita si fuese necesario, de un intérprete cuando no pudieren entender o hablar el idioma utilizado.

El acceso efectivo a la justicia, como casi todos los derechos humanos, no es absoluto y puede ser restringido de conformidad con las normas antes citadas, sin embargo, en el caso de éste las limitantes de esa naturaleza sólo pueden referirse a la necesidad de cumplir con los presupuestos formales y materiales de admisibilidad y procedencia para el tipo de acciones que se promuevan, pero nunca en una sociedad democrática podrá estar permitido el condicionar el ejercicio de ese derecho a la afectación o menoscabo de otro, pues ello no puede considerarse como un presupuesto, requisito, ni condición válida para acceder a la justicia. Menos, cuando justamente es el ejercicio del derecho al acceso a la 
justicia el que permite que sean revisadas por una autoridad competente las posibles violaciones de otros derechos humanos. En ese sentido, parece evidente la inconstitucionalidad de la fracción $\mathrm{V}$, del artículo 111.

Estrechamente vinculado con el acceso a la justicia y aunque es difícil plantearse por tratarse más bien de una omisión legislativa, el pretendido acceso a la justicia que se presume incorpora la Ley de Migración en los artículos 11 y 109, fracciones III a VI, para las personas migrantes "presentadas» $\mathrm{y}$ «alojadas», se hace nugatorio en la realidad y en el propio contenido de la ley al no establecerse los mecanismos idóneos para que se pueda ejercer de manera efectiva ese derecho, ya que, por ejemplo, no se abren posibilidades para que en aquellos casos en los que las leyes procesales piden la comparecencia, ratificación o presentación de manera personal de los recursos judiciales, esto se haga por un medio diferente y eficaz cuando se trate de personas privadas de la libertad en una estación migratoria. Esto, insisto, es más difícil de demostrar, pero no por ello debe dejar de intentarse, pues debemos tener presente siempre que sin acceso efectivo a la justicia, muchos otros derechos tampoco serían posibles al no poder reclamarse su violación o incumplimiento.

Lo analizado en esta tercera parte del documento es sólo una muestra de lo que considero son las más graves y evidentes inconstitucionalidades de la Ley de Migración mexicana por contravenir el contenido del bloque constitucional de derechos humanos. Además de ello, me generan importantes dudas, por su posible inconstitucionalidad, aspectos vinculados con la competencia y facultades que tienen el inm y la Secretaría de Gobernación para, por ejemplo, establecer o suprimir requisitos para el ingreso de extranjeros mediante disposiciones de carácter general publicadas en el Diario Oficial de la Federación (artículo 18, fracción II); para suspender o prohibir el ingreso de extranjeros en términos del Reglamento de la Ley (artículo 18, fracción III); para delegar en empresas de transporte de pasajeros la verificación y determinación de cuál es la documentación migratoria válida y vigente (artículo 44); para llevar a cabo funciones de control migratorio en lugares distintos a los destinados al tránsito internacional de personas (artículo 81); para recibir denun-

$176 \frac{\text { SEGUNDO SEMESTRE } 2014}{\text { MIGRACIÓN Y DESARROLLO NÚM. } 23}$ 
cias en contra de extranjeros (artículo 93); para llevar a cabo revisiones de carácter migratorio dentro del territorio nacional a efecto de comprobar la situación migratoria de los extranjeros (artículo 96); o también, la participación que se le da a la Policía Federal en acciones de control migratorio (artículo 81), traslado de extranjeros presentados o en proceso de retorno voluntario (artículo 105), entre algunas más. Todo esto, sin analizar el Reglamento de la ley, en el que, como podrá imaginarse, las inconstitucionalidades se multiplican.

Lo que aquí se ha expuesto sólo pretende ser un análisis ilustrativo, pero no taxativo de las inconstitucionalidades que contiene la Ley de Migración vigente mexicana. Busca ser una iniciativa para abrir a debate el contenido de la LM y, con ello, superar la normalidad pasiva que se tiene frente a las violaciones de los derechos humanos de las personas migrantes. Pero más bien, busca ser una pequeña muestra de lo mucho que queda por hacer y no hemos hecho en la defensa de los derechos de las personas migrantes en México.

\section{CONCLUSIÓN}

La manera de analizar la migración humana y calificarla como un hecho «bueno» o «malo» ha tenido muy cambiantes puntos de vista. Según la época de la historia humana que se analice, las variables económicas que se le impongan y el origen de dichos análisis, la conclusión a la que se llega en relación con la migración, la muestra como un proceso benéfico que suma al bienestar o como una de las fuentes de los peores fenómenos sociales. Esto ha generado que la migración en muchos casos sea analizada a partir de extremos que la muestran como estereotipos negativos de inseguridad, desempleo, dependencia, abuso, o bien evocan situaciones de máxima vulnerabilidad y victimización permanente. Parte de esos problemas tiene su origen en la construcción social de mitos en relación con la migración (número, origen, rutas, destino), con la transmisión de mensajes equivocados respecto a la realidad de ésta (criminalización, victimización, carga) y con prejuicios 
culturales y sociales de lo diferente, de lo que no se conoce (estereotipos religiosos, raciales, étnicos).

Todo ello, lo positivo y lo negativo, ha influido en la creación de las leyes que pretenden regular la migración, y el caso de México no es la excepción ya que, por una parte, se busca potenciar la presencia de los derechos humanos, pero, por otra parte, se sigue viendo a la migración como un problema de orden público y seguridad nacional. Esto genera que, pese a lo avanzado y proteccionista que puedan ser algunas de sus normas en la letra y el papel, en el fondo existen grandes contradicciones que, al final, se resuelven a partir de decisiones y actos discriminatorios que se cubren con el discurso de la actividad soberana del Estado. Inconsistencias e incongruencias que no sólo están en la LM, sino desde su antecedente normativo (LGP) y en otros ámbitos del sistema jurídico mexicano, pero que en este ámbito se agravan por la poca visibilidad que suele dárseles desde el derecho, al mantenerse aislado de otras disciplinas sociales.

En ese orden de ideas, la Ley de Migración mexicana, con apenas tres años de vigencia, se muestra como una oportunidad para mejorar la situación de las personas migrantes, para garantizar el derecho a migrar de toda persona. Pero para ello, esa ley necesita que sean expulsadas de su contenido todas aquellas normas que contradicen y vulneran los derechos reconocidos en el bloque constitucional de derechos humanos establecido en el artículo 10. constitucional, de lo contrario, poco se logrará transformar la realidad al mantenerse autorizadas situaciones que transgreden las bases del sistema jurídico mexicano en materia de derechos humanos.

Si la Ley de Migración, con todo y sus deficiencias, lograra materializarse en ese conjunto de normas que de manera positiva buscan proteger los derechos humanos de las personas migrantes, mucho podría aportar y servir de ejemplo a otros países. El gran reto está, por tanto, en cambiar ese conjunto de prácticas viciadas y desapego a la ley. La tarea está en sumar voluntades que hagan posible que no sólo en la letra, sino en la realidad, los derechos humanos sean una constante en la política migratoria mexicana, que ello sea en verdad el eje que guíe a la Ley de Migración.

$178 \frac{\text { SEGUNDO SEMESTRE } 2014}{\text { MIGRACIÓN Y DESARROLLO NÚM. } 23}$ 
El análisis que se ha hecho en este documento respecto a las posibles inconstitucionalidades de la Ley de Migración se puede compartir o no, pero en todo caso, representa una llamada de atención en cuanto a que existen ciertas inconsistencias que deben ser atendidas cuando éstas lleguen ante los órganos jurisdiccionales. Pero, sobre todo, una alerta para entender que el análisis que se haga de dicha ley, que está dirigida principalmente a personas extranjeras, no puede ser uno del tipo tradicional de derechos humanos, sino uno estricto y reforzado al estar siempre involucrada la obligación de no discriminar en razón de la nacionalidad, de salvaguardar el principio de igualdad contenido también en el artículo 1o. constitucional.

Lo aquí expresado es un análisis general que en mucho debe ser precisado aún. Lo desarrollado en este documento busca que iniciemos un trabajo para lograr que las normas que se han mencionado en el análisis o cualquier otra, sean declaradas inconstitucionales en beneficio de los derechos de las personas migrantes.

El camino es largo, como cuando se migra, y mucho falta por hacer. Si todos sumamos esfuerzos desde nuestros respectivos ámbitos cotidianos, podremos avanzar en el entendimiento de que todos somos iguales en derechos, que nuestra diversidad nos aporta mucho más que lo que aparentemente nos separa. Ojalá algún día entendamos que las fronteras no son esos límites que fijan los Estados, sino esos límites que nosotros nos ponemos al no buscar la igualdad de derechos para todos, respetando la diversidad.

\section{Biblografía}

CAstilla JuÁrez, Karlos (2009), «El principio pro persona en la administración de justicia», Cuestiones Constitucionales, núm. 20, pp. 65-83.

(2011), «Un nuevo panorama constitucional para el derecho internacional de los derechos humanos en México», Estudios Constitucionales, año 9, núm. 2, p. 147. (2013), «टंControl interno o difuso de convencionalidad? Una mejor idea: la garantía de tratados", Anuario Mexicano de Derecho Internacional, vol. xiII, pp. 51-97. 
Corte Interamericana de Derechos Humanos, La Expresión «Leyes» en el Artículo 30 de la Convención Americana sobre Derechos Humanos. Opinión Consultiva OC-6/86 del 9 de mayo de 1986. Serie A No. 6, párr. 38.

, Caso Gelman vs. Uruguay. Supervisión de Cumplimiento de Sentencia. Resolución de la Corte Interamericana de Derechos Humanos. 20 de marzo de 2013, párrs. 68, 88.

Fernández Rodríguez, José Julio (1998), La inconstitucionalidad por omisión: teoría general; derecho comparado; el caso español, Madrid, Civitas.

FiX Zamudio, Héctor (2013), «Los controles de constitucionalidad y convencionalidad en el ámbito interno: XI Congreso Iberoamericano de Derecho Constitucional», Instituto de Investigaciones Jurídicas de la UNAM, en: http://www.youtube.com/ watch? $v=y g P l k j F W Y r U$ (minuto 25, con 20 segundos y siguientes. Consultado el 5 de enero de 2013).

Guevara Bermúdez, José Antonio (2011), Marco institucional y normativo en materia de migración internacional en México, análisis y propuestas, documento de trabajo núm. 3, Instituto de Estudios y Divulgación sobre Migración A.C., pp. 107-110. instituto Nacional de Migración-Unidad de Política Migratoria (2012), Estadística Migratoria, Sintesis 2012, México, pp. 25-29. (2013), Estadística Migratoria, Sintesis 2013, México, pp. 29-33.

Morales VeGA, Luisa Gabriela (2012), "Categorías migratorias en México. Análisis a la Ley de Migración», Anuario Mexicano de Derecho Internacional, vol. XII, pp. 950-955.

Pérez García, Nancy (2010), «La importancia de una ley migratoria en México», Migración y Desarrollo, vol. 7, núm. 15, p. 186.

Relator Especial sobre los Derechos Humanos de los Migrantes, Informe a la Asamblea General de Naciones Unidas 2013 (A/68/283 de 7 de agosto de 2013), Sexagésimo octavo periodo de sesiones, párr. 8.

SÁnchez GIL, Rubén (2008), "La presunción de constitucionalidad», en Eduardo Ferrer MacGregor y Arturo Zaldívar Lelo de Larrea, La ciencia del derecho procesal constitucional. Estudios en homenaje a Héctor Fix Zamudio en sus cincuenta años como investigador del Derecho, t. vil, México, Instituto de Investigaciones Jurídicas de la UNAM, pp. 365-412.

Sin Fronteras (2014), La ruta del encierro. Situación de las personas en detención en estaciones migratorias y estancias provisionales 2013, México, Sin Fronteras, pp. 15-23.

$180 \frac{\text { SEGUNDO SEMESTRE } 2014}{\text { MIGRACIÓN Y DESARROLLO NÚM. } 23}$ 
Suprema Corte de Justicia de la Nación (2013), Protocolo de actuación para quienes imparten justicia en casos que afecten a personas migrantes sujetas de protección internacional, México, Suprema Corte de Justicia de la Nación, p. 20.

Tesis jurisprudencial 1a./J. 117/2012 (10a.).

Tesis jurisprudencial 1a./J. 118/2012 (10a.).

Tesis aislada 1a. XCIV/2013 (10a.).

Tesis jurisprudencial P./J. 80/2007 (9a.).

Tesis aislada 2a./J. 117/2007 (9a.).

Tesis jurisprudencial 2a./J. 45/200 (9a.).

Tesis jurisprudencial 1a./J. 2/2012 (9a.).

Tesis aislada 1a. XCI/2008 (9a.).

Tesis aislada I.30.C.681 C (9a.).

Tesis aislada VI.10.P.37 K (9a.).

Tesis aislada VIII.20.6 K (9a.).

Tesis aislada I.10.P.99 P (9a.).

Tesis aislada XXXIX/90 (8a.). 
